\title{
Sport and Recreation
}

01 DATA ANALYSIS OF THE SMART SPORTS INJURY REGISTRY FOR HIGH SCHOOL ATHLETES

doi:10.1136/injuryprev-2012-040590g.1

${ }^{1} \mathrm{~S}$ Jang, ${ }^{1} \mathrm{KD}$ Liller, ${ }^{2} \mathrm{~B}$ Morris, ${ }^{2} \mathrm{~J}$ Konin, ${ }^{1} \mathrm{~S}$ Wong. ${ }^{1}$ University of South Florida College of Public Health, US; ${ }^{2}$ University of South Florida College of Medicine, US

Background Due to the lack of comprehensive high school athletes' sports injury surveillance data in Florida, an injury registry was developed by the Sports Medicine and Athletic Related Trauma Institute (SMART) of the University of South Florida (USF), utilising Simtrak software. Data are collected by SMART-hired certified athletic trainers (ATCs) placed in Florida high schools.

Aims/Objectives/Purpose The purpose of this study is to provide the latest surveillance data (2010-2011) for injured high school athletes from the two large public high schools that have participated in the project since 2007.

Methods The ATCs collected practice and competition exposure, injury, and treatment data for leading high school sports. Data were analyzsd using Excel and SAS (V.9.2) at USF.

Results/Outcomes The ATCs supervised 713 athletes and were present at 1142 practices and 225 games. The leading rate of injury per 1000 athlete exposures for practices was for spring football (6.69), followed by football (2.97), and men's soccer (2.21). For competitions, the injury rates were greatest for women's track (12.4) followed by flag football (10.5), and football (9.82). Nearly $25 \%$ of the injuries were from students playing multiple sports. Sprains and strains were the leading injuries and leading body sites injured were the ankles, knees, and head.

Significance/Contribution to the Field The results of the SMART injury surveillance have led to targeted sports injury interventions and enhanced health of athletes. 